\title{
PinX1 Depletion Improves Liver Injury in a Mouse Model of Nonalcoholic Fatty Liver Disease via Increasing Telomerase Activity and Inhibiting Apoptosis
}

\author{
Erjiong Huang ${ }^{\mathrm{a}} \mathrm{Ke} \mathrm{Xu}^{\mathrm{b}} \quad$ Xuemei Gu${ }^{\mathrm{b}}$ Qihan Zhu ${ }^{\mathrm{b}}$ \\ aDepartment of Gastroenterology, The First Affiliated Hospital of Wenzhou Medical University, Wenzhou, China; \\ bepartment of Endocrinology, The First Affiliated Hospital of Wenzhou Medical University, Wenzhou, China
}

\section{Keywords}

PinX1 · NAFLD · Apoptosis · Lipid accumulation ·

Telomerase activity

\begin{abstract}
PIN2/TRF1-interacting telomerase inhibitor 1 (PinX1) can inhibit tumor growth by inhibiting telomerase activity. However, only few studies investigated the expression and function of PinX1 in nonalcoholic fatty liver disease (NAFLD). Thus, here we aimed to explore the roles of PinX1 in high-fat diet (HFD)-induced NAFLD in mice and in isolated hepatocytes. The mRNA expression of PinX1 and mTERT as well as telomere length were analyzed by RT-PCR. Pathological changes were detected by $\mathrm{HE}$ staining and oil red $\mathrm{O}$ staining. Triglyceride, cholesterol, alanine aminotransferase, aspartic aminotransferase, and telomerase activity were detected by ELISA. Hepatocyte apoptosis was determined by TUNEL and flow cytometry, and protein expression was analyzed by western blotting. We found that the expression of PinX1 was upregulated in the HFD group compared with the WT group. PinX1 knockout improved HFD-induced liver injury in mice and exhibited less lipid accumulation in hepatocytes. Moreover, telomere length, telomerase activity, and mTERT expression were significantly reduced in liver tissues of HFDinduced mice and palmitic acid-induced hepatocytes, while
\end{abstract}

PinX1 knockout attenuated the effect. Furthermore, HFD-induced $P$ in $X 1^{-1-}$ mice exhibited less hepatocyte apoptosis than HFD-induced WT mice. Besides, PinX1 knockout inhibited the increase of cleaved caspase- 3 and cleaved PARP expression in vivo and in vitro. Moreover, inhibition of mTERT reversed the effect of PinX1 knockout in hepatocytes. Taken together, our findings indicate that PinX 1 promotes hepatocyte apoptosis and lipid accumulation by decreasing telomere length and telomerase activity in the development of NAFLD. PinX1 might be a target for the treatment of NAFLD.

(C) 2021 The Author(s)

Published by S. Karger AG, Basel

\section{Introduction}

Nonalcoholic fatty liver disease (NAFLD) is a chronic metabolic disease, which is caused by non-alcohol and other definite liver injury factors [Wang and Malhi, 2018; Bessone et al., 2019]. A global epidemiological survey shows that the incidence rate of NAFLD is $25.24 \%$ (95\% CI: 22.10-28.65), increasing to $51.34 \%$ (95\% CI: $41.38-$ 61.20 ) in obese populations [Younossi et al., 2016]. Obesity, type 2 diabetes and hyperlipidemia are important risk factors for NAFLD [Li and Yang, 2018]. It is believed

E.H. and K.X. contributed equally to this study. karger@karger.com www.karger.com/cgr

Karger $\stackrel{\text { ' }}{5}$

GOPEN ACCESS
(C) 2021 The Author(s)

Published by S. Karger AG, Basel

This article is licensed under the Creative Commons Attribution 4.0 International License (CC BY) (http://www.karger.com/Services/ OpenAccessLicense). Usage, derivative works and distribution are permitted provided that proper credit is given to the author and the original publisher.
Correspondence to:

Xuemei Gu, xuemeigu1990@163.com

Qihan Zhu, qihanzhu1989@163.com 
that NAFLD will replace chronic viral liver disease and become the most common chronic liver disease in China [Zhang et al., 2018]. Therefore, the study of NAFLD is of great significance for the diagnosis and treatment of chronic liver disease in the future.

Telomeres consist of repetitive DNA sequences at the ends of chromosomes. Telomere shortening was associated with the increase of age and eventually leads to the replicative senescence of normal cells, cell cycle arrest, and apoptosis [Jiang et al., 2007; Shay, 2016]. In chronic liver injury, telomere shortening will be greatly accelerated due to the obvious acceleration of hepatocyte regeneration, which finally leads to liver fibrosis [Wiemann et al., 2002; Carulli, 2015; Laish et al., 2018].

PINX1 (Pin2/TRF1 interacting protein) is a newly discovered co-regulatory gene of telomerase and telomere, which is located on chromosome $8 \mathrm{p} 23$. PinX1 protein is 328 amino acids (aa) in length, with an hTERT binding site in the N-terminus (aa 1-142) and C-terminus (aa 254-328) [Liu et al., 2016]. Overexpression of PinX1 could significantly inhibit telomerase activity and thus suppress the growth of tumor cells in vitro and in vivo. The downregulation of PinX1, which could reduce the inhibition of telomerase activity and promote the growth of tumor, was related to the poor prognosis of many tumor cells [Yonekawa et al., 2012; Feng et al., 2017; Liang et al., 2018]. Telomerase activity was significantly decreased in patients with liver cirrhosis, and the expression of PinX1 was significantly higher than in patients without liver cirrhosis [El Idrissi et al., 2013]. The process of liver cirrhosis was related to the dysfunction of telomerase and the abnormal expression of some telomerase-related proteins [Nault et al., 2019]. At present, the role of PinX1 in NAFLD has not been studied.

In this study, we aimed to explore the function of PinX1 in NAFLD. NAFLD models in vivo and in vitro were established through high-fat diet (HFD) and palmitic acid (PA) treatment, respectively. The results indicated that knockout of PinX1 could improve HFD-induced liver injury, reduce hepatic lipid accumulation and hepatocyte apoptosis, and increase telomere length and telomerase activity in vitro and in vivo. PinX1 may become a potential target for the treatment of NAFLD.

\section{Materials and Methods}

\section{Animals and Groups}

Wild-type (WT) and PinX1 knockout $\left(\operatorname{PinX}^{-1-}\right.$ ) male C57BL/6 mice (18-20 g) were purchased from the Experimental Center of Nanjing Military General Hospital, Cyagen Biosciences Inc. (Su- zhou, China). WT or $\operatorname{Pin} X 1^{-1-}$ mice were randomly divided into 2 groups and fed with basic diet (ND; $21 \%$ protein, $6 \%$ fat, $55 \%$ carbohydrate) or high-fat diet (HFD; 83\% basic diet, 10\% lard, 5\% sucrose, $1.5 \%$ cholesterol, $0.5 \%$ bile salt), respectively. Each group (8 mice) was represented as WT-ND, $\operatorname{Pin} X 1^{-1-}-\mathrm{ND}$, WT-HFD, and PinX $1^{-1-}$-HFD, respectively. All mice were fed separately in cages, and the animal room was well ventilated, with room temperature of $18-25^{\circ} \mathrm{C}$, relative humidity of $40-60 \%$, and illumination time of $12 \mathrm{~h}$ per day. The experimental period was 8 weeks. The body weight and food intake of each mouse were recorded once a week, and changes in appearance and morphology, feeding behavior and external reaction of each group were observed every day.

\section{Tissue Samples}

Mice were euthanized by intraperitoneal injection of pentobarbital sodium $(120 \mathrm{mg} / \mathrm{kg})$. The liver tissues were quickly removed, and wet weight of liver was measured with electronic scales for calculating the liver index (liver wet mass/body mass $\times 100 \%$ ). Tissues $\left(3 \times 3 \mathrm{~mm}^{2}, 30 \mathrm{mg}\right)$ were taken from the middle of the left hepatic lobe with tweezers disinfected by high temperature, placed in a tube and stored at $-70^{\circ} \mathrm{C}$ for RT-PCR assay and ELISA assay. Tissues $\left(1 \times 0.5 \times 0.5 \mathrm{~cm}^{3}\right)$ from the edge of the part of the right liver lobe were also obtained for immunohistochemistry, HE staining, and oil red $\mathrm{O}$ staining.

\section{ELISA}

Blood was extracted from the abdominal aorta of the mice in each group, and the serum was obtained by centrifuging at 3,000 rpm for $5 \mathrm{~min}$. The serum triglyceride (TG), cholesterol (TC), alanine aminotransferase (ALT), and aspartic aminotransferase (AST) of the mice in each group were detected according to the manufacturer's instructions of the commercial reagent kit (Nanjing Jiancheng Bioengineering Institute, China).

\section{Reverse Transcription-PCR Assay}

Total RNA was extracted from liver tissue or hepatocytes using Trizol Reagent (Invitrogen, USA). The cDNA was obtained by reverse transcription with the PrimeScript Reverse-Transcription Reagent Kit (Thermo Fisher Scientific). SYBR Green qPCR Master Mix (Thermo Fisher Scientific) was used for RT-PCR assay in the Biosystems 7500 Sequence Detection System (Applied Biosystems, Foster City, CA, USA). The reaction conditions were as follows: preheating denaturation at $95^{\circ} \mathrm{C}$ for $15 \mathrm{~min}$, annealing at $94^{\circ} \mathrm{C}$ for $15 \mathrm{~s}$, extension at $51^{\circ} \mathrm{C}$ for $30 \mathrm{~s}$, reading plate at $72^{\circ} \mathrm{C}$ for $30 \mathrm{~s} ; 45$ cycles were performed. GAPDH was used for normalization. RNA expression was assessed using $2^{-\Delta \Delta \mathrm{Ct}}$ approach. The primer sequences are shown in Table 1.

\section{Telomere Length Measurement}

Total DNA was obtained from liver tissue or hepatocytes using AllPrep DNA Mini Kit (Qiagen). The 36B4 housekeeping gene was used as an endogenous calibrator. Then, $10 \mu \mathrm{L} 2 \times$ SYBR premix, $1 \mu \mathrm{L}$ upstream primer, $1 \mu \mathrm{L}$ downstream primer, $1 \mu \mathrm{L}$ template (or

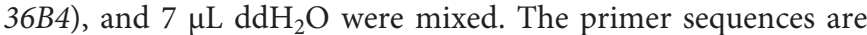
shown in Table 1 . The reaction conditions were as follows: $94^{\circ} \mathrm{C}$ for $1 \mathrm{~min}, 95^{\circ} \mathrm{C}$ for $10 \mathrm{~s}, 59^{\circ} \mathrm{C}$ for $10 \mathrm{~s}$, and $72^{\circ} \mathrm{C}$ for $10 \mathrm{~s}$ ( $40 \mathrm{cycles}$ ). The reactions were performed in the Biosystems 7500 Sequence Detection System and analyzed with qPCR 7500_Software_v2.0.5 (Applied Biosystems). Data were collected from triplicate reactions for each sample. The Ct values of each sample were extrapo- 
Table 1. List of primers for RT-PCR analysis

\begin{tabular}{|c|c|}
\hline Primers & Sequence $5^{\prime}-3^{\prime}$ \\
\hline PinX1-F & TITTCTCGAGATGTCTATGCTGGCTGAACG \\
\hline PinX1-R & TITTGAATTCTCATTTGGAATCTTTCTTC \\
\hline Telomere-F & CGGTTTGTTGGGTTTGGGTTGGGTTGGGTITGGGTT \\
\hline Telomere-R & GGCTTGCCTTACCCTTACССTTACССТTACССТTACССТ \\
\hline hTERT-F & CCGAGTGACCGTGGTTCTGTG \\
\hline hTERT-R & GGAAGCGGCGTTCGTTGTG \\
\hline GAPDH-F & ACCCCAGCAAGGACACTGAGCAAG \\
\hline GAPDH-R & GGCCCCTCCTGTTATTATTATGGGGGT \\
\hline
\end{tabular}

lated in their corresponding curves by a linear regression test. Results were calculated by the standard curve method. The standard curve of 36B4 was used as control.

\section{Telomerase Activity Assay}

Telomerase activity was measured by telomeric repeat amplification protocol (TRAP) ELISA kit (Boehringer, Mannheim, Germany) [Lamy et al., 2013], and the operation was carried out according to the manufacturer's instructions. Tissue protein was extracted by RIPA lysate and detected using a BCA kit. For telomerase reaction, $10 \mu \mathrm{L}$ protein solution (protein content of 10 $\mu \mathrm{g}$ ) was added to $25 \mu \mathrm{L}$ TRAP-PCR amplification solution, and was supplemented with sterile DEPC water to $50 \mu \mathrm{L}$. The reaction conditions were $94^{\circ} \mathrm{C}$ for $5 \mathrm{~min}, 94^{\circ} \mathrm{C}$ for $30 \mathrm{~s}, 50^{\circ} \mathrm{C}$ for $30 \mathrm{~s}, 72^{\circ} \mathrm{C}$ for $90 \mathrm{~s} ; 30$ cycles were performed. Then, $5 \mu \mathrm{L}$ of the above PCR product was mixed with $20 \mu \mathrm{L}$ denaturant and kept at room temperature for $10 \mathrm{~min}$. Following that, $225 \mu \mathrm{L}$ hybridization solution (containing digoxin labeled probe) was added to the mix, and then $100 \mu \mathrm{L}$ of the PCR product was coated in the anti-biotin enzyme label plate. Peroxidase was added to react with TMB substrate for $30 \mathrm{~min}$. The absorbance values at $450 \mathrm{~nm}$ and $690 \mathrm{~nm}$ were determined by fluorescence microplate reader (Thermo Fisher Scientific), and the value of $\mathrm{A}_{450}-\mathrm{A}_{690}$ represents telomerase activity.

\section{Oil Red O Staining}

The collected small pieces of liver tissue were embedded in optimal cutting temperature compound and stored at $-80^{\circ} \mathrm{C}$. Then, $8-\mu \mathrm{m}$ slices were obtained by frozen sectioning technique. The sections were fixed with $95 \%$ ethanol, soaked with $60 \%$ isopropanol for $2 \mathrm{~min}$, stained with oil red $\mathrm{O}$ working solution for $30 \mathrm{~min}$, soaked with $60 \%$ isopropanol until the background was colorless, washed with $\mathrm{dd}_{2} \mathrm{O}$ for 3 times, re-stained with hematoxylin for 2 min, cleaned with $\mathrm{ddH}_{2} \mathrm{O}$ for 3 times, and sealed with neutral resin. The results were observed and photographed with an optical microscope (Olympus, Tokyo, Japan). The lipid droplets were orange red and the nuclei were blue.

\section{Hematoxylin Eosin Staining}

Liver tissues were fixed with $4 \%$ paraformaldehyde and then embedded in paraffin. 4- $\mu \mathrm{m}$ tissue sections were obtained by conventional serial sections. After dewaxing and rehydration, the slices were stained with hematoxylin staining solution for $10 \mathrm{~min}$, washed with $\mathrm{ddH}_{2} \mathrm{O}$ for 3 times, and stained with eosin staining solution for $1 \mathrm{~min}$. After dehydration, the sections were sealed with neutral resin. The results were observed and photographed with a light microscope (Olympus, Tokyo, Japan). The nuclei were blue and the cytoplasm was pink.

\section{Immunohistochemical Assay}

Immunohistochemical staining was performed according to the previous study [Yang et al., 2020]. Briefly, the liver tissues were first fixed in $4 \%$ paraformaldehyde. Consecutive $4-\mu \mathrm{m}$ sections were cut for immunohistochemical analysis. The sections were blocked with $4 \%$ BSA for $30 \mathrm{~min}$, and then incubated with antiPinX1 antibodies (Santa Cruz Biotechnology, Dallas, TX, USA) for $2 \mathrm{~h}$ at room temperature. Following that, the goat anti-rabbit secondary antibody with high-sensitivity streptavidin-HRP conjugate was used (Santa Cruz Biotechnology). The results were visualized by diaminobenzidine (DAB) according to the instruction. Images were taken with a microscope (Nikon, Tokyo) and analyzed by Image J $1.48 \mathrm{v}$ software $(\mathrm{NIH})$.

\section{TUNEL Assay}

After dewaxing and rehydration, paraffin sections were incubated with $3 \%$ hydrogen peroxide for $10 \mathrm{~min}$ at room temperature, washed with PBS for 3 times, digested with protease $\mathrm{K}$ working solution at $37^{\circ} \mathrm{C}$ for $20 \mathrm{~min}$, and washed with PBS for 3 times, and then added into TUNEL reaction solution (Roche). After incubation at $37^{\circ} \mathrm{C}$ for $1 \mathrm{~h}$, the sections were washed for 3 times with PBS and nuclei were counterstained with DAPI for $1 \mathrm{~min}$ at room temperature in the dark. The cells with green nuclei were TUNELpositive cells. Apoptosis index $=$ TUNEL positive cells/total cells $\times$ $100 \%$.

\section{Western Blot}

The total protein of liver tissue and cells was extracted by RIPA reagent (Vazyme, USA). The concentration of protein was determined by BCA kit (Vazyme, USA). Then, proteins were separated by $12 \%$ polyacrylamide gel electrophoresis (SDS-PAGE) and transferred to a PVDF membrane, which was blocked with $5 \%$ skim milk powder at room temperature. Anti-PinX1 (1:1,000), anti-caspase-3 (1:1,000), anti-cleaved caspase-3 (1:1,000), and antiGAPDH $(1: 1,000)$ were incubated overnight at $4^{\circ} \mathrm{C}$. HRP-labeled secondary antibodies $(1: 5,000)$ were incubated at room temperature for $2 \mathrm{~h}$. Bound antibodies were visualized by chemiluminescence. Images were taken and analyzed using Bio-Rad ChemiDoc $\mathrm{XRS}+$ (Bio-Rad, CA, USA). Antibodies used in western blots were purchased from Cell Signaling Technology (Beverly, MA, USA).

\section{Isolation and Culture of Hepatocytes}

Primary hepatocytes from WT and $\mathrm{PinX} 1^{-/-}$mice were obtained according to a previous study [Shibany et al., 2016]. After the mice were killed, the infusion eluent (PBS, $4 \mathrm{mmol} / \mathrm{L} \mathrm{NaOH}$, $10 \mathrm{mmol} / \mathrm{L}$ HEPES, $0.5 \mathrm{mmol} / \mathrm{L}$ EDTA, pH7.8) was injected into the inferior vena cava in the right atrium of the heart and drained from the portal vein, so that the blood cells in the liver were washed out. Following that, the liver was removed, placed in a plate, and further perfused with the digestive solution (PBS, $4 \mathrm{mmol} / \mathrm{L}$ $\mathrm{NaOH}, 10 \mathrm{mmol} / \mathrm{L}$ HEPES, and $0.4 \mathrm{mg} / \mathrm{mL}$ collagenase II, $\mathrm{pH} 7.8$ ) for $15 \mathrm{~min}$. The digested cell slurry was filtered through a $100-$ mesh filter, centrifuged at $500 \mathrm{~g}$ for $1 \mathrm{~min}$, the supernatant was removed, and then $5 \mathrm{~mL}$ of DMEM/F12 medium containing HEPES (10 mM) and FBS (10\%) was added. Percoll (GE Healthcare Life Sciences) was further used to separate hepatocytes. Then, the 
cells $\left(1 \times 10^{5} / \mathrm{mL}\right)$ were collected and seeded in 6 -well plates coated with collagen type I, and cultured at $37^{\circ} \mathrm{C}, 5 \% \mathrm{CO}_{2}$ with William's E medium containing cell maintenance supplements (Combo kit CM400 from Gibco). The hepatocytes were treated for $24 \mathrm{~h}$ with $0.32 \mathrm{~mm}$ PA or the same volume of normal saline.

\section{Cell Apoptosis Assay}

Cells were washed in PBS for 3 times, and then collected and resuspended at $1 \times 10^{6} / \mathrm{mL}$ in serum-free DMEM medium. The cell suspension $(100 \mu \mathrm{L})$ was mixed with $5 \mu \mathrm{L}$ Annexin V-FITC and incubated for $15 \mathrm{~min}$ at room temperature. The cells were centrifuged at $1,000 \mathrm{~g}$ for $5 \mathrm{~min}$, resuspended in $100 \mu \mathrm{L}$ of precooled binding buffer, mixed with $10 \mu \mathrm{L}$ propidium iodide (PI), and incubated overnight at $4^{\circ} \mathrm{C}$. Cell apoptosis was detected by a flow cytometer (BD AccuriTM C6, MA, USA).

\section{Statistical Analysis}

All data were analyzed by SPSS version 18.0 (IBM SPSS, NY, USA). The measurement data were expressed as mean \pm standard deviation; Student $t$-test was used for comparison, one-way ANOVA was used for comparison between groups. $p<0.05$ was considered to be statistically significant.

\section{Results}

Effect of PinX1 on Body Weight and Liver Index in the NAFLD Mouse Model

We used an HFD-induced NAFLD mouse model to study the role of PinX1 in the development of NAFLD. The results of immunohistochemical staining showed that more PinX1-positive cells were present in the WTHFD group than in the WT group; no PinX1-positive cells were found in $\mathrm{PinX} 1^{-/-}$and $\mathrm{PinX} 1^{-/-}$-HFD groups (Fig. 1a). Western blot and RT-PCR were used to detect the expression of PinX1 in liver tissues of mice in each group, and the results were consistent with those of immunohistochemistry (Fig. 1b-d). The results indicated that HFD could induce upregulation of PinX1, and knockout of PinX1 significantly inhibited the expression of PinX1. In addition, knockout of PinX1 could attenuate the effect of HFD on body weight and liver index of the mice (Fig. 1e, f).

\section{PinX1 Knockout Inhibits Liver Injury in the NAFLD Mouse Model}

The results of HE and oil red O staining showed that the liver tissue structure of the WT and PinX1 $1^{-1-}$ groups was natural, the morphology of hepatocytes was normal, the arrangement was orderly, the cytoplasm was dyed red, the nuclei were large and round, there was no obvious lesion, and there were no obvious orange red lipid droplets in the cells. In the WT-HFD group, liver tissue was disor- dered and steatosis was obvious, distinct swelling of hepatocytes was observed, the position of nuclei deviated from the center, and large red-stained lipid droplets could be seen in the cells. However, the pathological damage of liver tissue in $P$ in $X 1^{-1-}$-HFD mice was significantly improved (Fig. 2a, b). Moreover, the contents of TG and TC and the activities of ALT and AST were significantly higher in the WT-HFD group than in the WT-ND group, and were lower in the PinX1 $1^{-1-}$-HFD group than in the WTHFD group (Fig. 2c-f). Our findings indicated that knockout of PinX1 could attenuate liver injury and fat accumulation in HFD-induced mice, and decreased the contents of TG and TC and the activities of ALT and AST.

\section{PinX1 Knockout Enhanced Telomerase Activity and}

Prevented Telomere Shortening in the NAFLD Mouse Model

Shortening telomere length can affect liver cell growth and lead to an increased risk of cirrhosis [Wan et al., 2012]. Moreover, studies have shown that telomerase activity is associated with the development of NAFLD. Therefore, telomere length and telomerase activity in liver tissue were detected by RT-PCR and ELISA, respectively. The results showed that telomere length and telomerase activity were significantly reduced in the WTHFD group, and telomere length was significantly increased and telomere activity was promoted in the Pin $X 1^{-/-}$-HFD group compared with the WT-HFD group (Fig. 3a, b). Moreover, mTERT mRNA and protein expression were detected by RT-PCR and western blot, respectively. mTERT expression was lower in the WT-HFD group, and mTERT expression was significantly upregulated in the PinX1 $1^{-/-}$-HFD group compared with the WTHFD group (Fig. $3 \mathrm{c}-\mathrm{e}$ ). The results indicated that knockout of PinX1 reversed the effect of HFD on telomere length and telomerase activity in mice.

\section{PinX1 Knockout Inhibited Hepatocyte Apoptosis in} the NAFLD Mouse Model

Hepatocyte apoptosis was also detected by TUNEL in the NAFLD mouse model. The results showed that the apoptosis index (50\%) of hepatocytes in the WT-HFD group was significantly higher than that (20\%) in the WT group, and apoptosis index (30\%) of hepatocytes in the PinX1 $1^{-/}$ -HFD group was significantly decreased compared to that (50\%) in the WT-HFD group (Fig. 4a). Furthermore, expression of apoptosis-related proteins was detected by western blot. The results showed that the expression of PARP and caspase- 3 did not change significantly between the 2 groups. Cleaved PARP and cleaved caspase- 3 expres- 


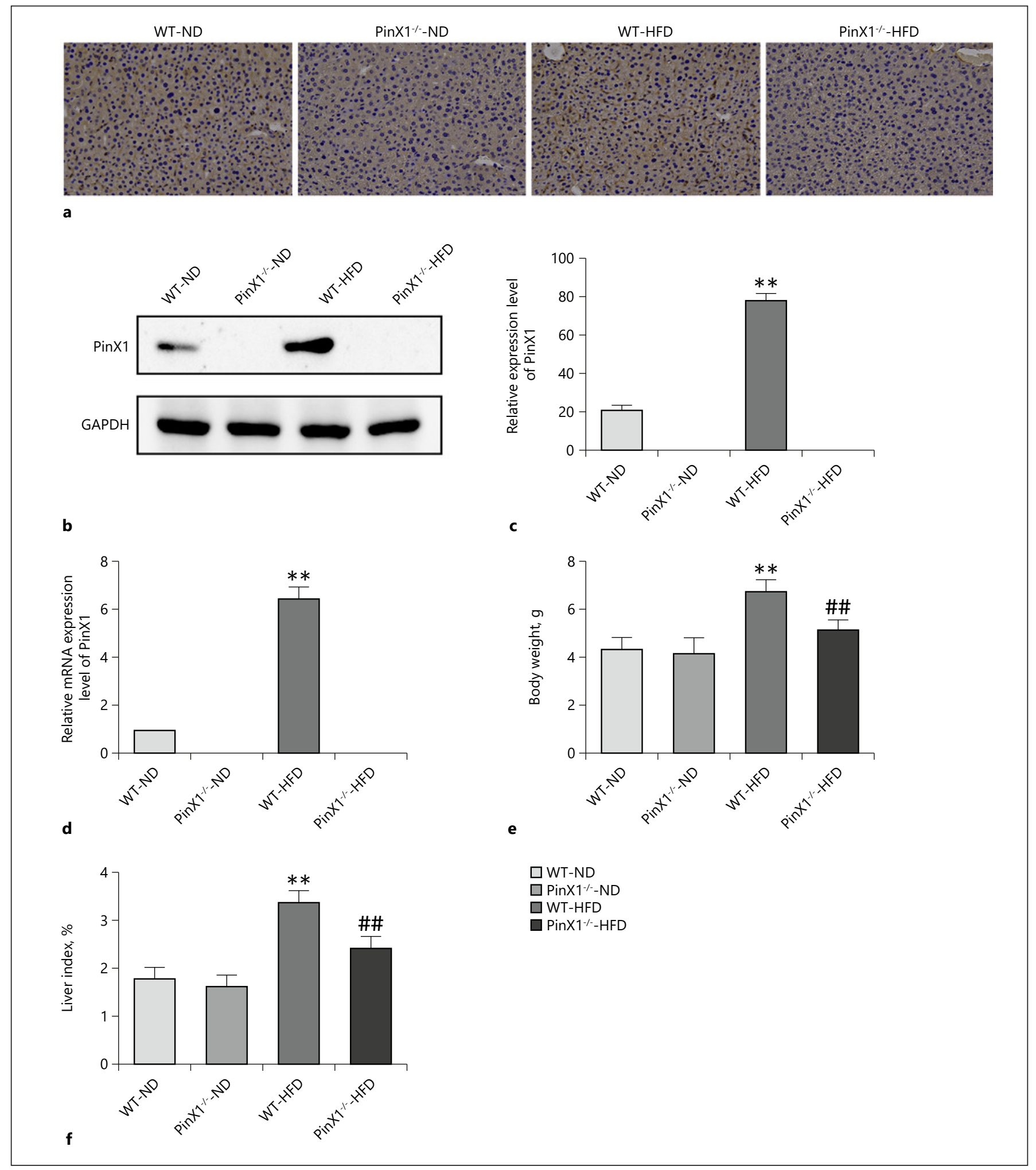

Fig. 1. The expression of PinX1 was blocked in $P$ inX $X 1^{-1-}$ mice fed basic diet (ND) or high-fat diet (HFD), and PinX1 knockdown decreased body weight and liver index of mice with HFD. Immunohistochemical staining (a), western blot (b), and RT-PCR (c, d) was used to detect PinX1 expression. e Body weight. f Liver index. ${ }^{* *} p<0.01$ versus WT-ND group; ${ }^{\# \#} p<0.01$ versus WT-HFD group. 


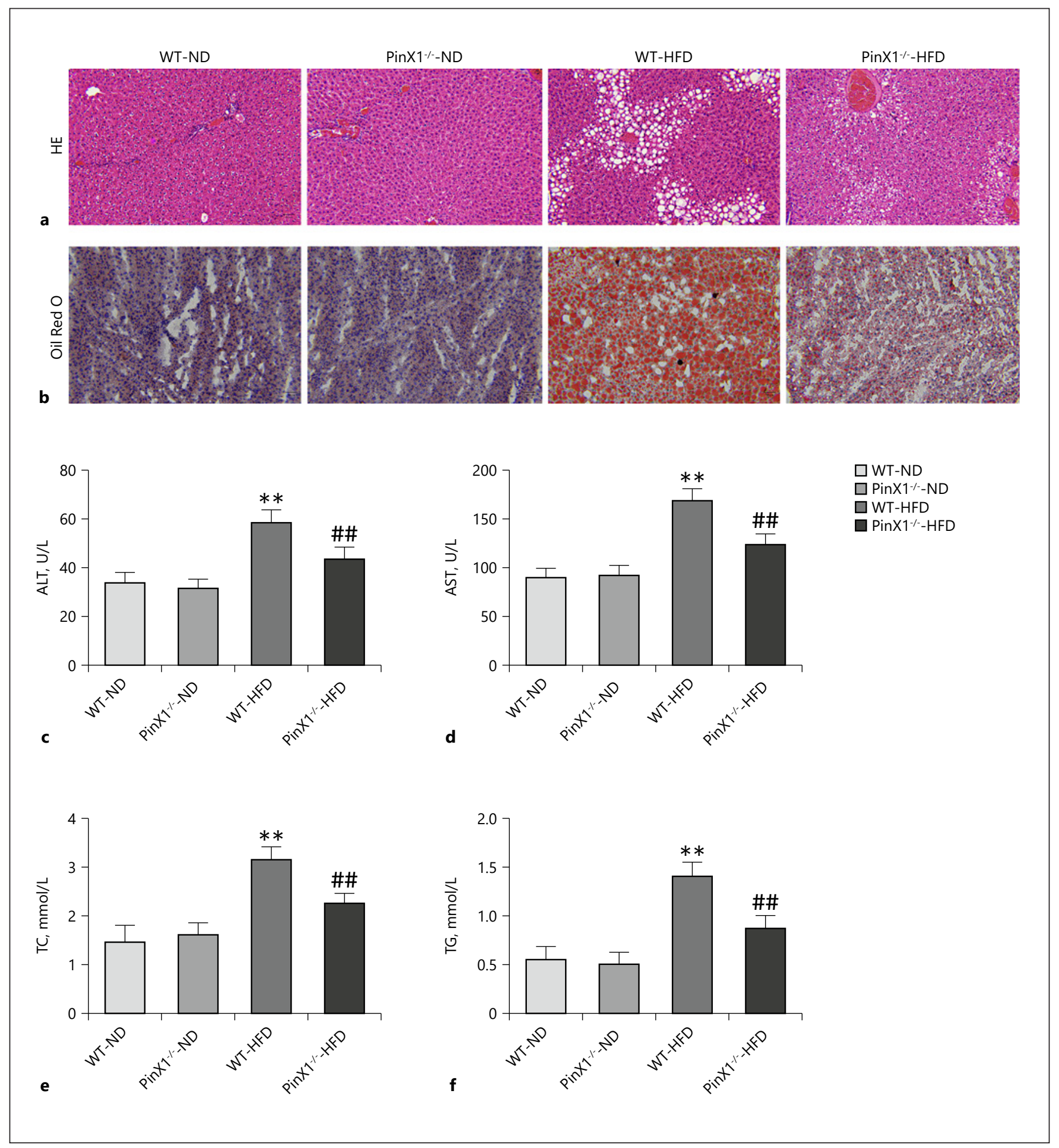

Fig. 2. PinX1 knockout reduced liver injury in the nonalcoholic fatty liver disease mouse model. a, b Pathological changes were detected by $\mathrm{HE}$ and oil red $\mathrm{O}$ staining. c-f Serum alanine aminotransferase (ALT), aspartic aminotransferase (AST), triglyceride
(TG), and cholesterol (TC) levels were detected by the corresponding reagent kits. ${ }^{* *} p<0.01$ versus WT-ND group; ${ }^{\# \#} p<0.01$ versus WT-HFD group. 


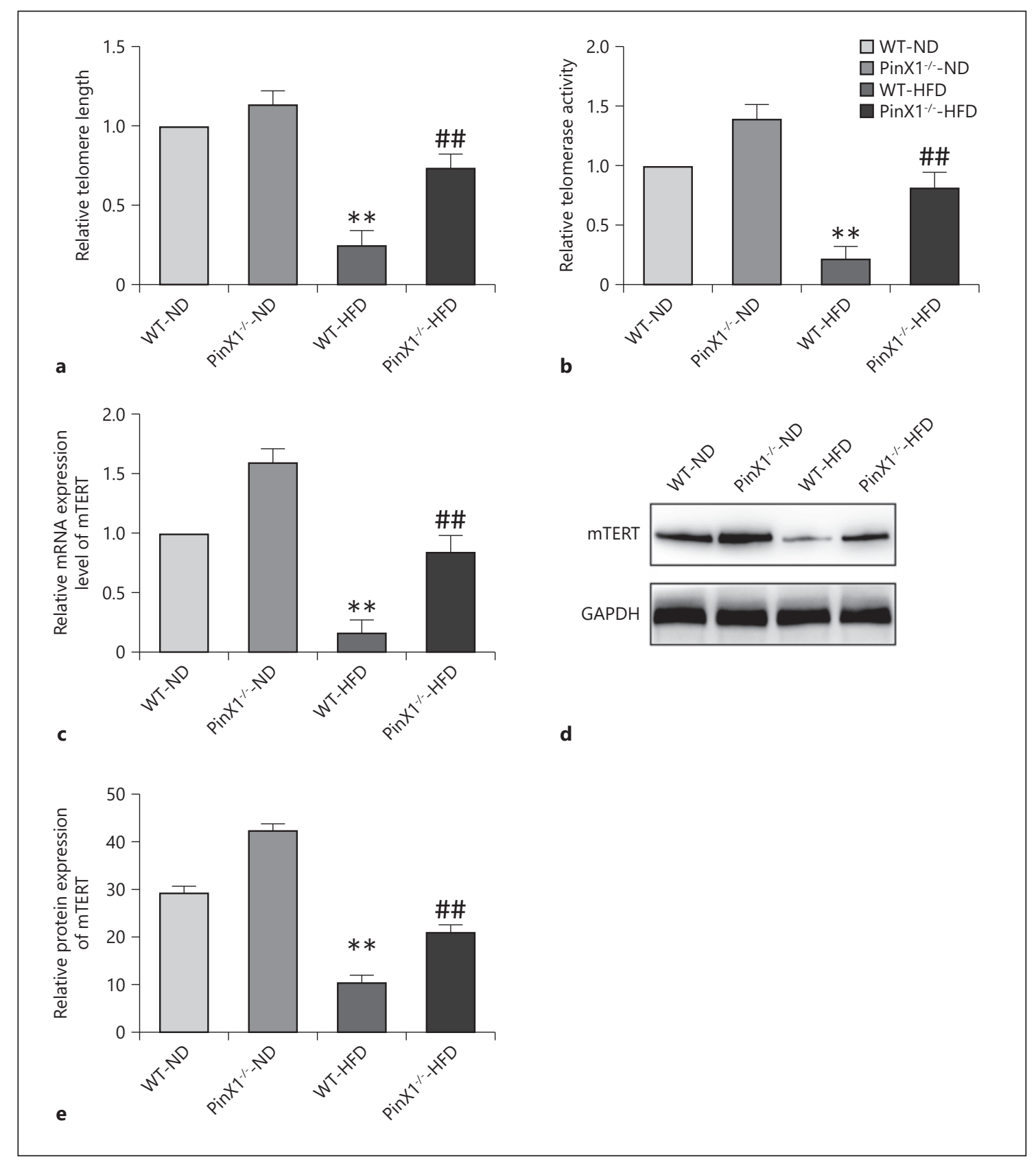

Fig. 3. PinX1 knockout increased telomere length and telomerase activity in the nonalcoholic fatty liver disease mouse model. a RTPCR was used to detect telomere length. b TRAP ELISA kit was used to detect telomerase activity. c RT-PCR was used to detect the

sions were significantly increased in the WT-HFD group compared to the WT group, while cleaved PARP and caspase-3 expressions were significantly reduced in the Pin $X 1^{-1-}$-HFD group compared to the WT-HFD group (Fig. 4b, c). In conclusion, silencing PinX1 ameliorated the increase of hepatocyte apoptosis induced by HFD.
mRNA level of mTERT. d, e Protein expression of mTERT was measured by western blot. ${ }^{* *} p<0.01$ versus WT-ND group; ${ }^{\# \#} p<$ 0.01 versus WT-HFD group.

\section{PinX1 Knockdown Attenuated Metabolism}

Parameter (TG, TC, ALT, and AST) Levels and Fat

Accumulation in PA-Induced Hepatocytes

PinX1 expression was detected by western blot in hepatocytes from WT and PinX1 $1^{-1-}$ mice. Compared with the WT + control group, PinX1 expression was increased 
DAPI
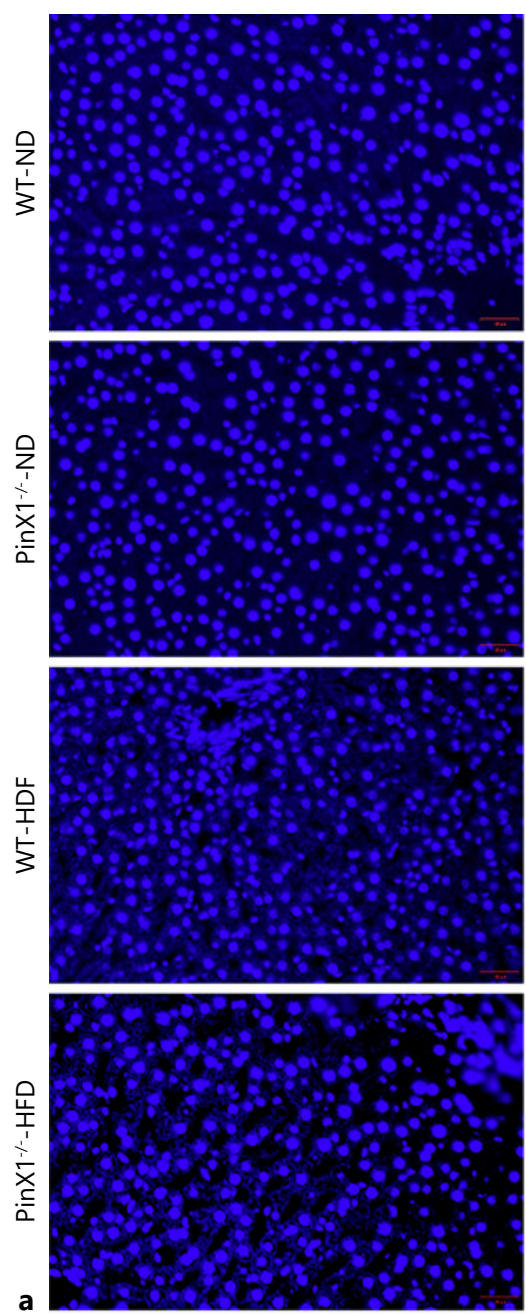

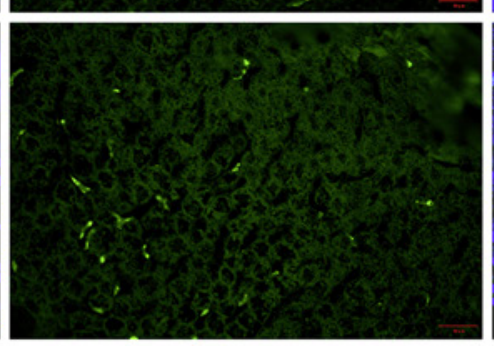

Merge
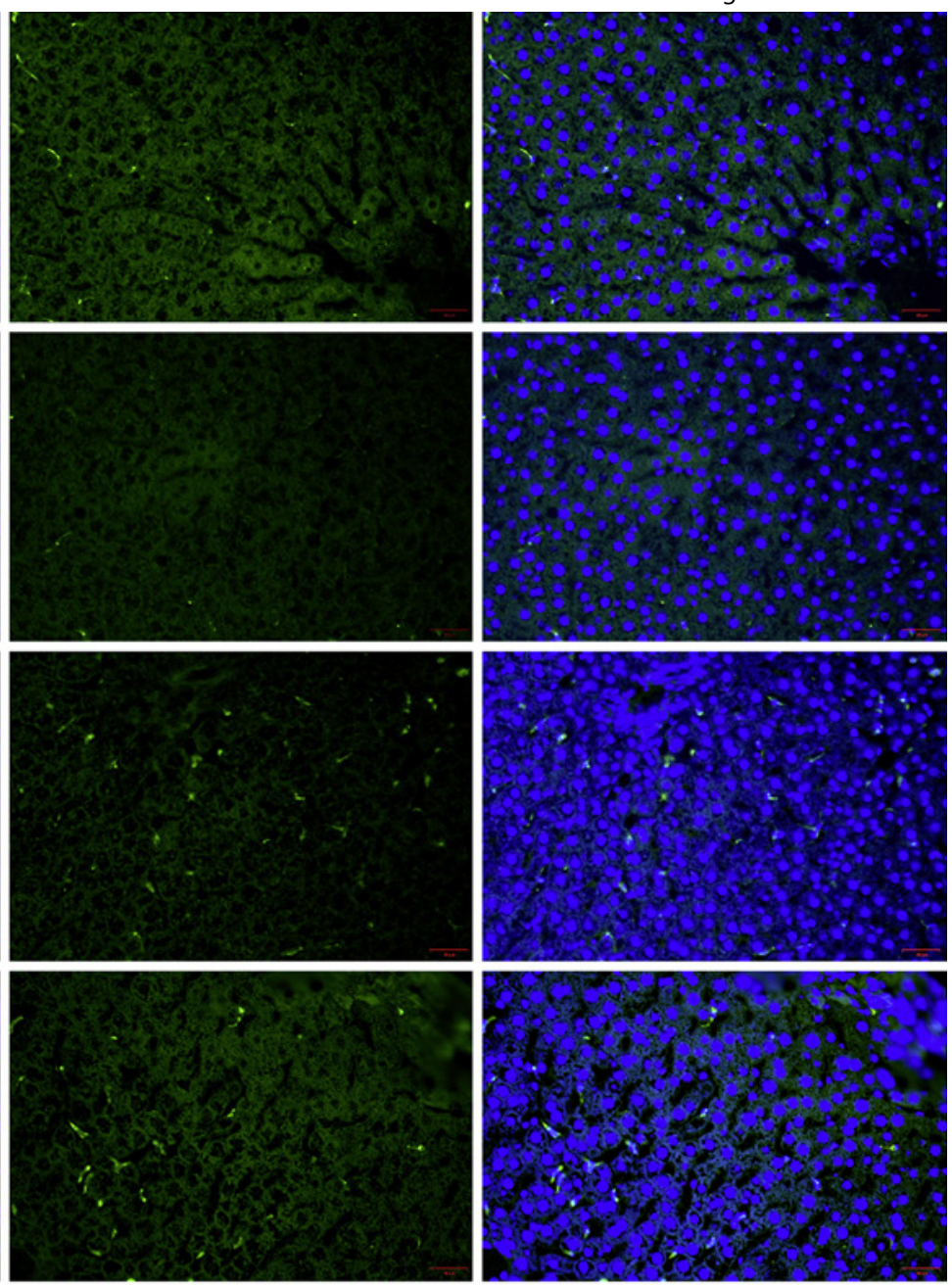
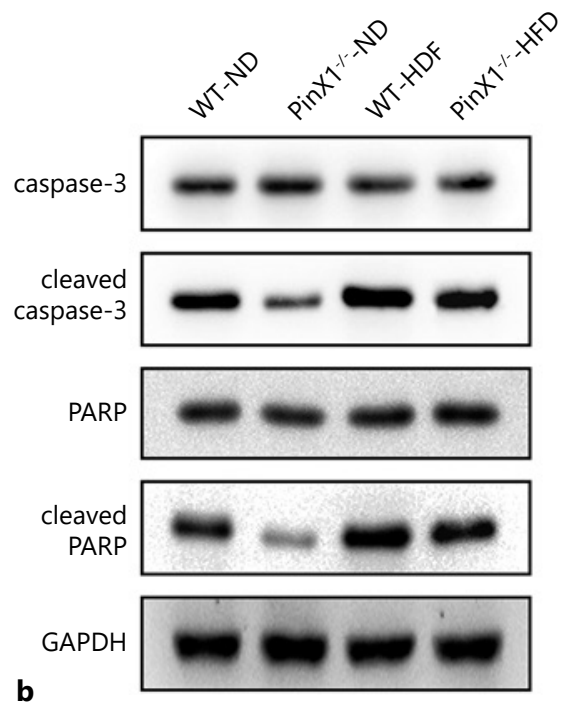

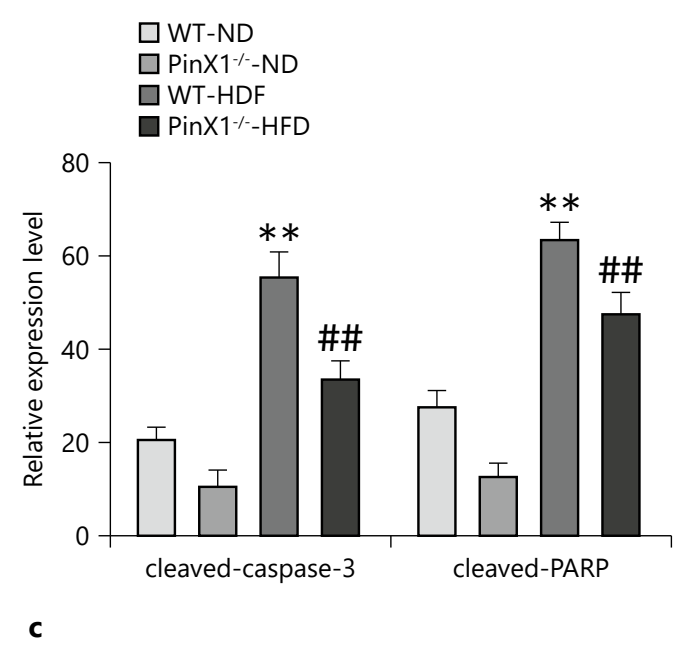

(For legend see next page.) 

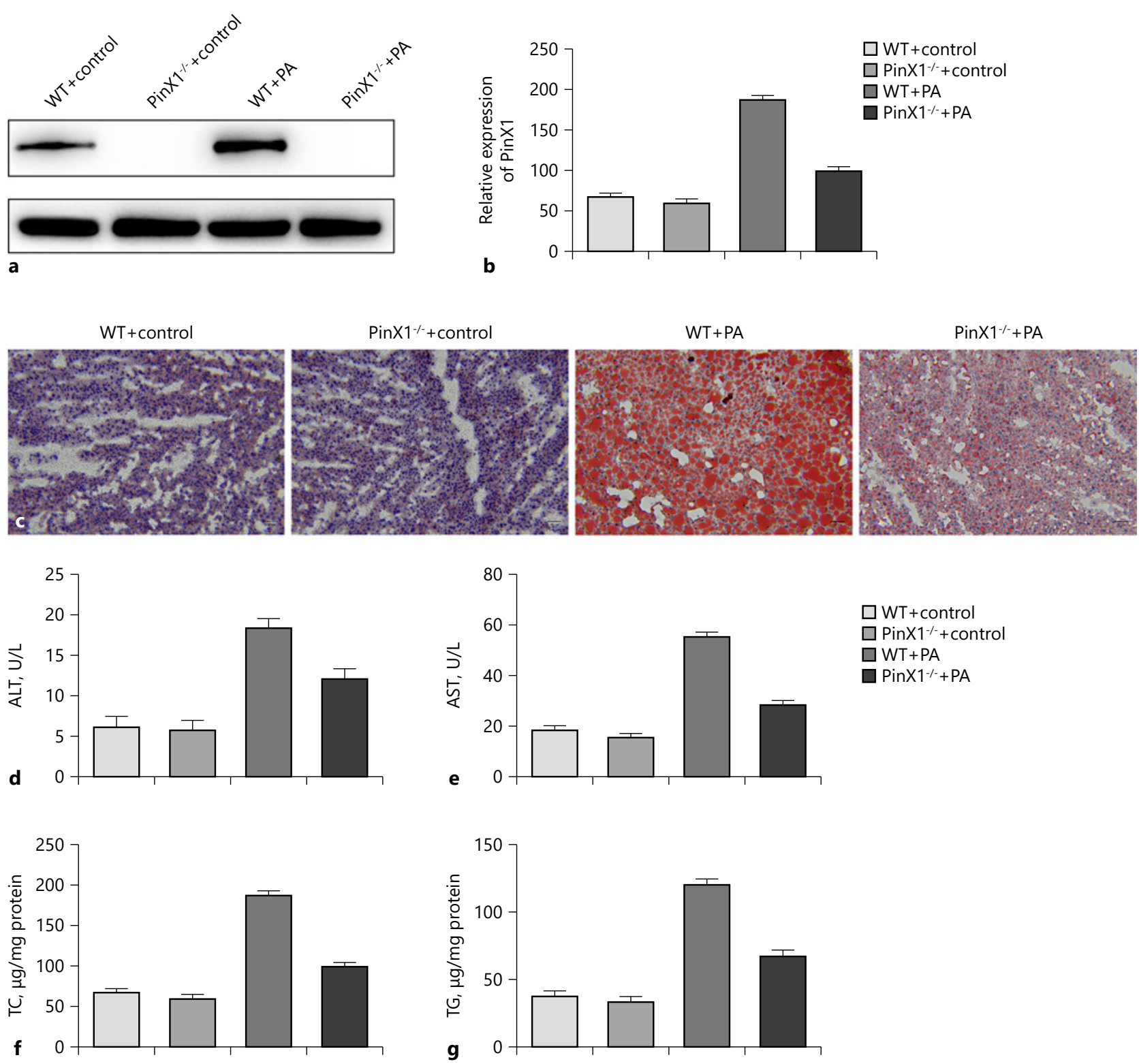

Fig. 5. PinX1 knockout reduced lipid accumulation and glucose and lipid metabolism in hepatocytes induced by palmitic acid (PA). a, b Expression of PinX1 was measured by western blot. c Oil red $\mathrm{O}$ staining was performed in hepatocytes isolated from WT mice and $\mathrm{PinX}^{-/-}$mice. $\mathbf{d}-\mathbf{g}$ Serum alanine aminotransferase (ALT), aspartic aminotransferase (AST), triglyceride (TG), and cholesterol (TC) levels were measured by the corresponding reagent kits.
Fig. 4. PinX1 knockout inhibited hepatocyte apoptosis of liver tissues in the nonalcoholic fatty liver disease mouse model. a TUNEL assay was used to detect hepatocyte apoptosis in liver tissues. b, c
Western blot was used to detect the expression of caspase- 3 , cleaved caspase-3, PARP, and cleaved PARP. ${ }^{* *} p<0.01$ versus WT-ND group; ${ }^{\# \#} p<0.01$ versus WT-HFD group. 

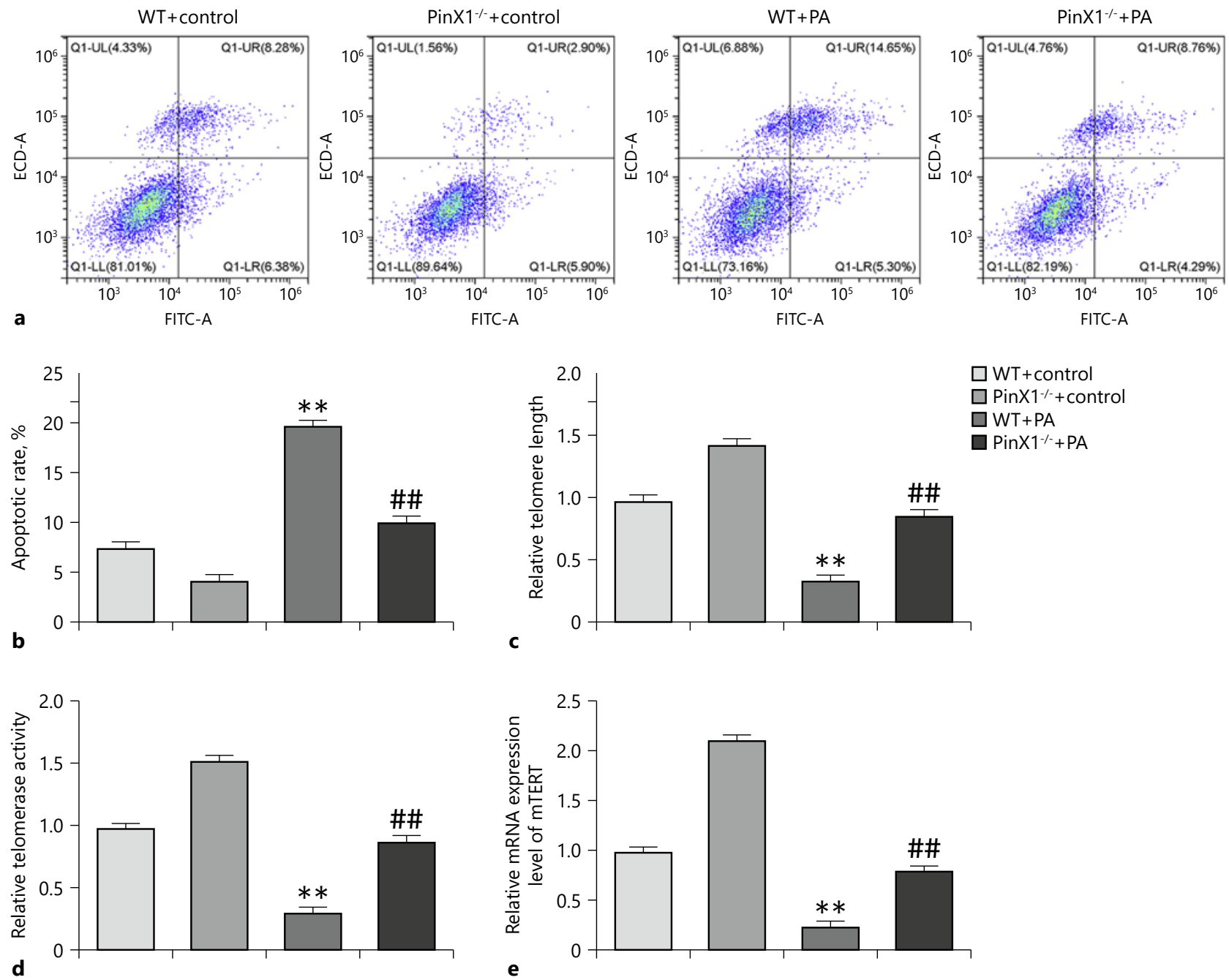

Fig. 6. PinX1 knockout attenuated palmitic acid (PA)-induced hepatocyte apoptosis and telomerase inactivation. $\mathbf{a}, \mathbf{b}$ Cell apoptosis was detected by flow cytometry in hepatocytes induced by PA. c Telomere length was measured by RT-PCR. $\mathbf{d}$ Telomerase activ-

in the WT + PA group, and there was no PinX1 expression in $\mathrm{PinX} 1^{-/-}+$control and $\mathrm{PinX} 1^{-/-}+\mathrm{PA}$ groups (Fig. 5a, b). PA-induced hepatocytes showed increased lipid droplets, and PinX1 knockdown reduced the formation of lipid droplets (Fig. 5c). Moreover, contents of TG and TC and the activities of ALT and AST were enhanced in PA-induced hepatocytes, but this was reversed by PinX1 deletion (Fig. 5d-g). Altogether, the results indicated that PinX1 knockdown reduced the PA-induced hepatocyte injury. ity was measured by TRAP ELISA kit. $\mathbf{e}$ The mRNA level of mTERT was detected by RT-PCR. ${ }^{* *} p<0.01$ versus $\mathrm{WT}+$ control group; ${ }^{\# \#} p<0.01$ versus $\mathrm{WT}+\mathrm{PA}$ group.

\section{PinX1 Knockdown Reduced PA-Induced Hepatocyte} Apoptosis and Inactivation of Telomerase

Hepatocyte apoptosis has been reported to be a symbol of liver injury in NAFLD. Hence, detection of hepatocyte apoptosis was performed. The results of flow cytometry demonstrated that PA-induced increase of apoptosis in hepatocytes from WT mice was reversed by PinX1 knockdown (Fig. 6a, b). Further, telomere length and telomerase activity were drastically reduced in hepatocytes treated with PA, while PinX1 deletion significantly repressed the effect (Fig. 6c, d). mTERT mRNA expression was also measured by RT-PCR. The level of mTERT mRNA was 


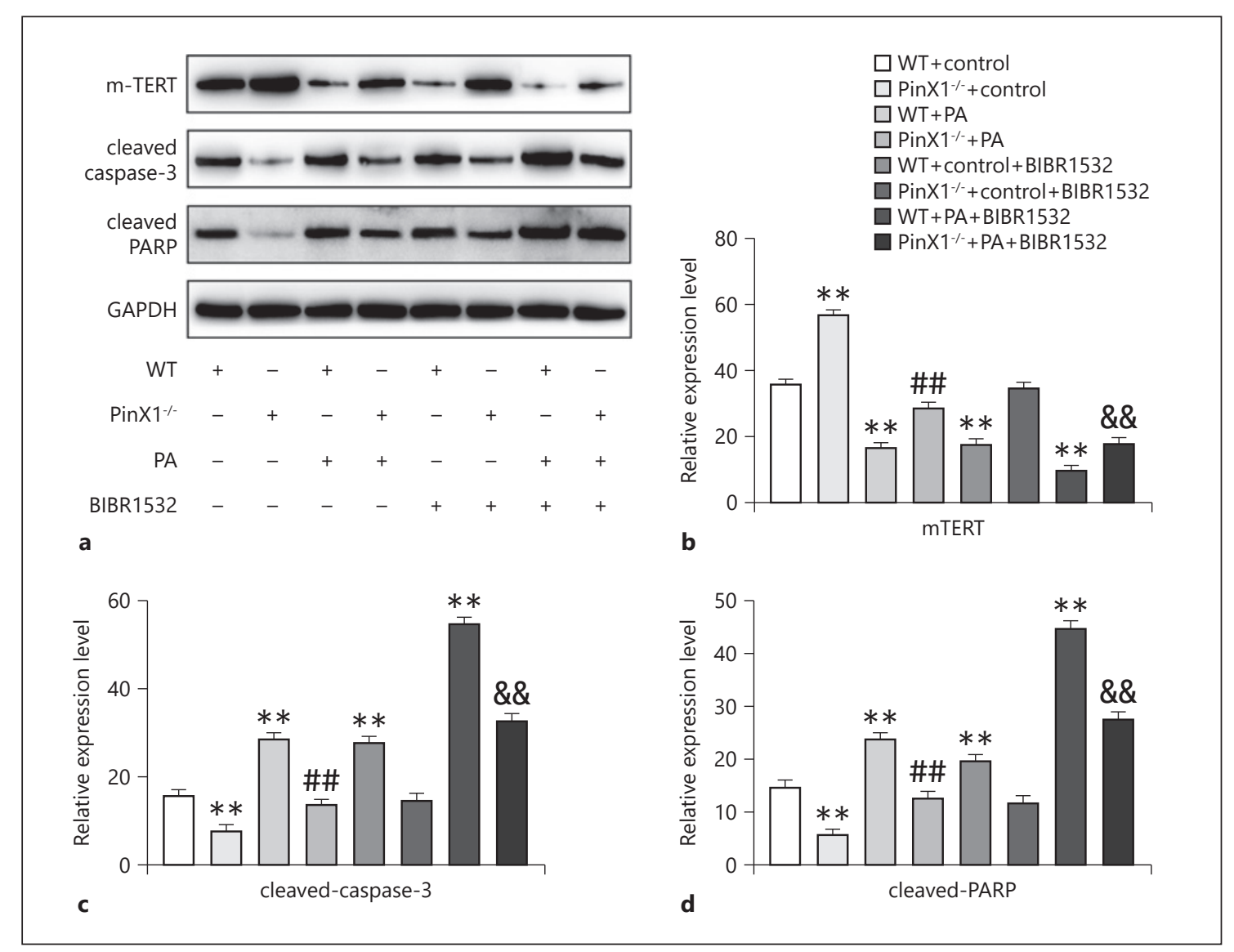

Fig. 7. PinX1 knockout inhibited apoptosis relative protein expression via modulated mTERT. Hepatocytes isolated from WT mice and $P$ in $X 1^{-1-}$ mice were treated with palmitic acid (PA), and BIBR1532, an inhibitor of mTERT, was used to treat cells to in- hibit mTERT activation. a-d Expression of mTERT, cleaved caspase-3, and cleaved PARP was measured by western blot. ${ }^{* *} p<$ 0.01 versus $\mathrm{WT}+$ control group; ${ }^{\# \#} p<0.01$ versus $\mathrm{WT}+\mathrm{PA}$ group; $\& \& p<0.01$ versus $P$ inX $1^{-l-}+$ PA group. obviously decreased in PA-treated hepatocytes, but loss of PinX1 attenuated the downregulation of mTERT induced by PA (Fig. 6e). Altogether, the data suggested that PinX1 deletion alleviated PA-induced hepatocyte apoptosis and telomerase activity in vitro.

\section{PinX1 Knockdown Increased mTERT Expression and Then Attenuated Hepatocyte Apoptosis}

To investigate the role of mTERT-mediated apoptosis in the protective effect of PinX1 knockdown on PA-induced hepatocytes, an inhibitor of mTERT, BIBR1532, was used. First, BIBR1532 or/and PA reduced the expression of mTERT. Interestingly, PinX1 knockout increased mTERT expression, and the effect was reversed by BIBR1532 treatment. In addition, BIBR1532 or/and PA could increase the expression of cleaved caspase-3 and cleaved PARP, while PinX1 knockout inhibited their ex- pression, and BIBR1532 treatment could terminate this effect (Fig. 7). The protective effect of PinX1 knockout on PA-induced hepatocytes may be achieved by regulating the expression of mTERT.

\section{Discussion}

Our results showed that knockout of PinX1 increased telomere length and telomerase activity, and thus alleviated the progression of NAFLD in vivo and in vitro. Moreover, in vitro, it was demonstrated that knockout of PinX1 reduced hepatocyte apoptosis by upregulating mTERT.

With the change of people's lifestyle and the change of diet structure, the incidence rate of NAFLD is increasing year by year. Some patients develop cirrhosis and even 
liver cancer [Friedman et al., 2018]. At present, the research on the pathogenesis of NAFLD mainly focuses on the abnormal lipid metabolism, oxygen stress and lipid peroxidation damage, the role of genetic factors, insulin resistance, and so on [Neuschwander-Tetri, 2017; Sookoian and Pirola, 2019]. Telomerase inhibitor PINX1 is a novel tumor suppressor gene cloned from yeast. It is located at chromosome $8 \mathrm{p} 23$ and consists of 7 exons, encoding 328 amino acids. PinX1 protein contains 2 domains: the G-patch, which is common in RNA-binding proteins or damage repair factors, and the telomerase inhibition domain [Zhang et al., 2014; Fu et al., 2017; Ho et al., 2019]. Studies have shown that PinX1 plays an important role in the progression of a variety of tumors, but studies in chronic liver disease are rare, and research about NAFLD has not yet been reported. In this paper, our data showed that PinX1 was upregulated in an HFDinduced NAFLD mouse model compared with the WTND group. Moreover, PinX1 expression was increased in hepatocytes treated with PA. PinX1 knockout mitigated the increase of body weight and liver index induced by HFD. The results of pathological analysis illustrated that PinX1 knockout could inhibit the HFD-induced liver injury in mice. In addition, silencing of PinX1 attenuated the increase of serum TG, TC, ALT, and AST levels induced by HFD in mice. TG, TC, ALT, and AST levels of the supernatant of hepatocytes treated with PA were reduced by PinX1 knockout. These results suggested that knockout of PinX1 alleviated the progression of NAFLD in vivo and in vitro.

PinX1 as a major tumor suppressor is essential for maintaining chromosome stability. Moreover, silencing of PinX1 causes aberrant telomerase activation, which induces chromosome instability and cancer initiation [Zhou et al., 2011]. Studies have confirmed that PinX1 inhibits the growth of tumor cells by directly inhibiting telomerase reverse transcriptase (hTERT) [Lin et al., 2007; Lai et al., 2012; Zuo et al., 2013]. hTERT is one of the core components of telomerase, which is the limiting factor of telomerase activity. Telomeres are composed of repeated DNA sequences (TTAGGG) and a specialized protein complex called telosome. They are located at the 2 ends of a linear chromosome. Their function is to protect the chromosome from the damage of nuclease and ligase [Blasco, 2005]. Telomerase is an enzyme protein complex, including 2 basic components: telomerase reverse transcriptase (hTERT) and telomerase RNA (hTERC). The enzyme complex is responsible for synthesizing new DNA sequences and adding them to the ends of chromosomes to maintain telomere length. However, during each cell division, the telomere length will be gradually shortened because the end part of a chromosome is not completely copied by DNA polymerase [Zvereva et al., 2010; Arndt and MacKenzie, 2016]. Previous studies specifically addressed telomerase deficiency and hepatopathy (NAFLD and cirrhosis) [Donati and Valenti, 2016; Laish et al., 2016; Donati et al., 2017]. Kitada et al. [1995] first demonstrated the relationship between telomere shortening and cirrhosis in 1995. The telomere length in liver cirrhosis and hepatitis was shorter than that of normal liver tissue, especially in liver cirrhosis. Studies have shown an association between telomere length and NAFLD [Aravinthan et al., 2013; Kim et al., 2018]. Compared with the control group, NAFLD patients had shorter telomeres, which were related to the degree of fatty liver disease, the increase of p21, and steatohepatitis. The results suggested that the aggravation of steatosis and cell damage accelerated telomere loss, induced cell cycle arrest, and hindered liver regeneration [Aravinthan et al., 2013]. In our study, the results indicated that telomeres were shortened, telomerase activity was decreased, and mTERT expression was increased in the HFD-induced NAFLD mouse model and in PA-induced hepatocytes, while PinX1 knockout inhibited these effects. Hence, silencing PinX1 increased the telomere length and telomerase activity, which might be a reason for ameliorating the liver injury of NAFLD.

Apoptosis is the programmed death of cells after receiving certain signals or being stimulated by certain factors. Caspase- 3 is a cysteine protease that promotes apoptosis; it is at the core of the apoptosis process and is the key protein of apoptosis. PARP is the substrate of caspase-3, and its cleavage is a sign of cell apoptosis [Li et al., 2019]. Abnormal regulation of apoptosis plays an important role in the pathogenesis of viral, nonalcoholic, druginduced liver diseases and hepatocellular carcinoma [Khan et al., 2017]. At present, more and more evidence indicated that hepatocyte apoptosis might be a key step in the development of NAFLD, and also an important marker of the progression [Ipsen et al., 2018; Kanda et al., 2018]. Rubicon (a regulator for autophagosome-lysosome fusion) was highly expressed in an HFD-induced NAFLD mouse model, and Rubicon knockout could improve hepatocyte damage in NAFLD by inhibiting hepatocyte apoptosis and lipid accumulation, and promoting autophagy [Tanaka et al., 2016]. Interferon gene stimulating factor (STING) and its downstream factor interferon regulatory factor 3 (IRF3) promoted the process of NAFLD by increasing inflammation and apoptosis of hepatocytes and interfering with glucose and lipid metabo- 
lism. In our results, we found that the number of TUNELpositive cells in the liver tissue of mice with HFD-induced NAFLD was significantly increased compared to that in the WT group. However, PinX1 knockout significantly inhibited the HFD-induced increase of TUNEL-positive cells compared with the WT group, and the expression of cleaved caspase- 3 and cleaved PARP were increased in HFD-induced NAFLD mice. PinX1 knockout inhibited this effect. Similar results were also found in PA-induced hepatocytes. These data indicated that knockout of PinX1 significantly reduced hepatocyte apoptosis in HFD-induced mice and PA-induced hepatocytes. At the cellular levels, the results demonstrated that inhibition of mTERT abolished the effect of PinX1 knockout on decrease of apoptosis in PA-induced hepatocytes.

\section{Conclusion}

PinX1 plays an important role in the process of NAFLD. PinX1 can enhance liver injury by reducing telomere length, inhibiting telomerase activity, and inducing hepatocyte apoptosis in the HFD-induced NAFLD mouse model. Moreover, knockout of PinX1 can improve the progression of NAFLD. Our experiments provide new clues for researching gene therapy of NAFLD. Our results suggest that PinX1 might be a potential therapeutic target for the treatment of NAFLD.

\section{Statement of Ethics}

All experiments were performed in the First Affiliated Hospital of Wenzhou Medical University, and approved by the Animal Ethics Committee of the First Affiliated Hospital of Wenzhou Medical University. Animals were cared for in accordance with the Animal Care and Use of the First Affiliated Hospital of Wenzhou Medical University.

\section{Conflict of Interest Statement}

The authors have no conflicts of interest to declare.

\section{Funding Sources}

No funding was received for this study.

\section{Author Contributions}

Q.Z.: concept, design, and critical review. E.H.: design, supervision, manuscript writing. K.X.: materials, data collection and processing. X.G.: data collection and processing, analysis and interpretation, and literature search.

\section{Data Availability Statement}

The datasets used and/or analyzed during the current study are available from the corresponding author on reasonable request.

\section{References}

Aravinthan A, Scarpini C, Tachtatzis P, Verma S, Penrhyn-Lowe S, Harvey R, et al. Hepatocyte senescence predicts progression in non-alcohol-related fatty liver disease. J Hepatol. 2013; 58:549-56.

Arndt GM, MacKenzie KL. New prospects for targeting telomerase beyond the telomere. Nat Rev Cancer. 2016;16:508-24.

Bessone F, Razori MV, Roma MG. Molecular pathways of nonalcoholic fatty liver disease development and progression. Cell Mol Life Sci. 2019;76:99-128.

Blasco MA. Telomeres and human disease: ageing, cancer and beyond. Nat Rev Genet. 2005; 6:611-22.

Carulli L. Telomere shortening as genetic risk factor of liver cirrhosis. World J Gastroenterol. 2015;21:379-83.

Donati B, Valenti L. Telomeres, NAFLD and Chronic Liver Disease. Int J Mol Sci. 2016;17: 383.

Donati B, Pietrelli A, Pingitore P, Dongiovanni P, Caddeo A, Walker L, et al. Telomerase reverse transcriptase germline mutations and hepatocellular carcinoma in patients with nonalco- holic fatty liver disease. Cancer Med. 2017;6: 1930-40.

El Idrissi M, Hervieu V, Merle P, Mortreux F, Wattel E. Cause-specific telomere factors deregulation in hepatocellular carcinoma. J Exp Clin Cancer Res. 2013;32:64.

Feng YZ, Zhang QY, Fu MT, Zhang ZF, Wei M, Zhou JY, et al. Low expression of PinX1 is associated with malignant behavior in basal-like breast cancer. Oncol Rep. 2017;38:109-19.

Friedman SL, Neuschwander-Tetri BA, Rinella M, Sanyal AJ. Mechanisms of NAFLD development and therapeutic strategies. Nat Med. 2018;24:908-22.

Fu X, Wen H, Jing L, Yang Y, Wang W, Liang X, et al. MicroRNA-155-5p promotes hepatocellular carcinoma progression by suppressing PTEN through the PI3K/Akt pathway. Cancer Sci. 2017;108:620-31.

Ho ST, Jin R, Cheung DH, Huang JJ, Shaw PC. The PinX1/NPM interaction associates with hTERT in early-S phase and facilitates telomerase activation. Cell Biosci. 2019;9:47.

Ipsen DH, Lykkesfeldt J, Tveden-Nyborg P. Molecular mechanisms of hepatic lipid accumu- lation in non-alcoholic fatty liver disease. Cell Mol Life Sci. 2018;75:3313-27.

Jiang H, Ju Z, Rudolph KL. Telomere shortening and ageing. Z Gerontol Geriatr. 2007;40:31424.

Kanda T, Matsuoka S, Yamazaki M, Shibata T, Nirei $\mathrm{K}$, Takahashi $\mathrm{H}$, et al. Apoptosis and nonalcoholic fatty liver diseases. World J Gastroenterol. 2018;24:2661-72.

Khan HA, Ahmad MZ, Khan JA, Arshad MI. Crosstalk of liver immune cells and cell death mechanisms in different murine models of liver injury and its clinical relevance. Hepatobiliary Pancreat Dis Int. 2017;16:245-56.

Kim D, Li AA, Ahmed A. Leucocyte telomere shortening is associated with nonalcoholic fatty liver disease-related advanced fibrosis. Liver Int. 2018;38:1839-48.

Kitada T, Seki S, Kawakita N, Kuroki T, Monna T. Telomere shortening in chronic liver diseases. Biochem Biophys Res Commun. 1995;211:33-9.

Lai XF, Shen CX, Wen Z, Qian YH, Yu CS, Wang JQ, et al. PinX1 regulation of telomerase activity and apoptosis in nasopharyngeal carcinoma cells. J Exp Clin Cancer Res. 2012;31:12. 
Laish I, Mannasse-Green B, Hadary R, BironShental T, Konikoff FM, Amiel A, et al. Telomere Dysfunction in Nonalcoholic Fatty Liver Disease and Cryptogenic Cirrhosis. Cytogenet Genome Res. 2016;150:93-9.

Laish I, Mari A, Mannasse B, Hadary R, Konikoff FM, Amiel A, et al. Telomere Length, Aggregates, and Capture in Cirrhosis. Isr Med Assoc J. 2018;20:295-9.

Lamy E, Herz C, Lutz-Bonengel S, Hertrampf A, Márton MR, Mersch-Sundermann V. The MAPK pathway signals telomerase modulation in response to isothiocyanate-induced DNA damage of human liver cancer cells. PLoS One. 2013;8:e53240.

Li J, Wang Q, Wang Z, Cui N, Yang B, Niu W, et al. Tetrandrine inhibits colon carcinoma HT29 cells growth via the Bcl-2/Caspase 3/PARP pathway and G1/S phase. Biosci Rep. 2019;39: BSR20182109.

Li L, Yang X. The Essential Element Manganese, Oxidative Stress, and Metabolic Diseases: Links and Interactions. Oxid Med Cell Longev. 2018;2018:7580707.

Liang H, Xiong Z, Li Y, Kong W, Yao Z, Li R, et al. Prognostic and Clinicopathological Value of PINX1 in Various Human Tumors: A Meta-Analysis. Biomed Res Int. 2018;2018: 4621015.

Lin J, Jin R, Zhang B, Yang PX, Chen H, Bai YX, et al. Characterization of a novel effect of hPinX1 on hTERT nucleolar localization. Biochem Biophys Res Commun. 2007;353: 946-52.
Liu X, Li J, Qin F, Dai S. miR-152 as a tumor suppressor microRNA: Target recognition and regulation in cancer. Oncol Lett. 2016;11: 3911-6.

Nault JC, Ningarhari M, Rebouissou S, ZucmanRossi J. The role of telomeres and telomerase in cirrhosis and liver cancer. Nat Rev Gastroenterol Hepatol. 2019;16:544-58.

Neuschwander-Tetri BA. Non-alcoholic fatty liver disease. BMC Med. 2017;15:45.

Shay JW. Role of Telomeres and Telomerase in Aging and Cancer. Cancer Discov. 2016;6: 584-93.

Shibany KA, Tötemeyer S, Pratt SL, Paine SW. Equine hepatocytes: isolation, cryopreservation, and applications to in vitro drug metabolism studies. Pharmacol Res Perspect. 2016; 4:e00268.

Sookoian S, Pirola CJ. Genetics of Nonalcoholic Fatty Liver Disease: From Pathogenesis to Therapeutics. Semin Liver Dis. 2019;39:12440.

Tanaka S, Hikita H, Tatsumi T, Sakamori R, Nozaki Y, Sakane S, et al. Rubicon inhibits autophagy and accelerates hepatocyte apoptosis and lipid accumulation in nonalcoholic fatty liver disease in mice. Hepatology. 2016;64: 1994-2014.

Wan S, Hann HW, Myers RE, Fu X, Hann RS, $\mathrm{Kim} \mathrm{SH}$, et al. Telomere length in circulating serum DNA as a novel non-invasive biomarker for cirrhosis: a nested case-control analysis. Liver Int. 2012;32:1233-41.

Wang XJ, Malhi H. Nonalcoholic Fatty Liver Disease. Ann Intern Med. 2018;169:ITC65-80.

Wiemann SU, Satyanarayana A, Tsahuridu M, Tillmann HL, Zender L, Klempnauer J, et al. Hepatocyte telomere shortening and senescence are general markers of human liver cirrhosis. FASEB J. 2002;16:935-42.
Yang Y, Lin J, Guo S, Xue X, Wang Y, Qiu S, et al. RRM2 protects against ferroptosis and is a tumor biomarker for liver cancer. Cancer Cell Int. 2020;20:587.

Yonekawa T, Yang S, Counter CM. PinX1 localizes to telomeres and stabilizes TRF1 at mitosis. Mol Cell Biol. 2012;32:1387-95.

Younossi ZM, Koenig AB, Abdelatif D, Fazel Y, Henry L, Wymer M. Global epidemiology of nonalcoholic fatty liver disease - Meta-analytic assessment of prevalence, incidence, and outcomes. Hepatology. 2016;64:73-84.

Zhang R, Zhao J, Wang X, Wang LL, Xu J, Song C. PinX1 without the G-patch motif suppresses proliferation, induces senescence, but does not inhibit telomerase activity in colorectal cancer SW480 cells. Oncol Rep. 2014;32:28692.

Zhang X, Ji X, Wang Q, Li JZ. New insight into inter-organ crosstalk contributing to the pathogenesis of non-alcoholic fatty liver disease (NAFLD). Protein Cell. 2018;9:164-77.

Zhou XZ, Huang P, Shi R, Lee TH, Lu G, Zhang $\mathrm{Z}$, et al. The telomerase inhibitor PinX1 is a major haploinsufficient tumor suppressor essential for chromosome stability in mice. J Clin Invest. 2011;121:1266-82.

Zuo J, Wang DH, Zhang YJ, Liu L, Liu FL, Liu W. Expression and mechanism of PinX1 and telomerase activity in the carcinogenesis of esophageal epithelial cells. Oncol Rep. 2013; 30:1823-31.

Zvereva MI, Shcherbakova DM, Dontsova OA Telomerase: structure, functions, and activity regulation. Biochemistry (Mosc). 2010;75: 1563-83. 